\title{
CONSTRUCTION and EARLY COMMISSIONING RESULTS of the AGS BOOSTER:
}

\author{
W. T. WENG, L. AHRENS, R. DAMM and A. J. MCNER ËY \\ BROOKHAVEN NATIONAL LABORATORY \\ UPTON, NEW YORK 11973
}

DE91 014024

\begin{abstract}
The AGS Booster synchrotron bas been designid to accelerate protons from $200 \mathrm{MeV}$ to $1.5 \mathrm{GeV}$ and heavy ions from several $\mathrm{MeV}$ per nucleon to several hundred $\mathrm{MeV}$ per nucleon for all the nuclei up to gold. The design requirements and measurement results of major accelerator components and systems are presented. The early commissioning results of the injection is also presented.
\end{abstract}

\section{INTRODUCTION}

The circumference of the Booster ring is $201.78 \mathrm{M}$, onequarter of that of the AGS. The ring consists of 24 FODO cells and has tune of about 4.82 in both planes. Twelve straight sections are created by the missing magnet scheme resulting in 36 dipoles, each providing $10^{\circ}$ bend.

The Booster receives a $200 \mathrm{MeV}$ proton beam from the Linac through the Linac-to-Booster (LTB) transfer line, accelerites it to $1.5 \mathrm{GeV}$ in 63 msec, and feeds four pulses into the AGS at $7.5 \mathrm{~Hz}$ rate through the Booster-to-AGS (BTA) line. It also receives heavy ion beams from the Tandem Van de Granff through HITL-to-Booster (HTB) line, a $900 \mathrm{M}$ long transfer line. The Booster accelerates the heavy ions to their find energy in about $0.5 \mathrm{sec}$ and feeds one pulse to the AGS for physics research or for future injection into the RHIC ring. The layout of the Booster ring and its three beam transfer lines is shown in Figure 1.

Detailed design parameters and complete component specifications of the Booster can be found in the Booster Design Manual [1]. In reference [2], important design issues and their solutions for fast cycling high intensity proton acceleration has been reported. In Section II, the design issues and solutions for heavy ion operation will be discussed. In Section III, the test results of some of the accelerator systems and the early commissioning are presented.

\section{DESIGN ISSUES for HEAVY ION ACCELERATION}

\section{A. Ultra-High Vacuum}

The heavy ions coming out of the Tandem do not bave high enough energy to be fully stripped. Current vecuum in the AGS ring is a few $10^{\circ}$ Torr, only nuclei with mass number less than sulfur can bave reasonable survival rate inside the AGS vacuum, see Figure 2. The Booster is designed to hrve vacuum in the range of $10^{-10}$ to $10^{-11}$ Tor

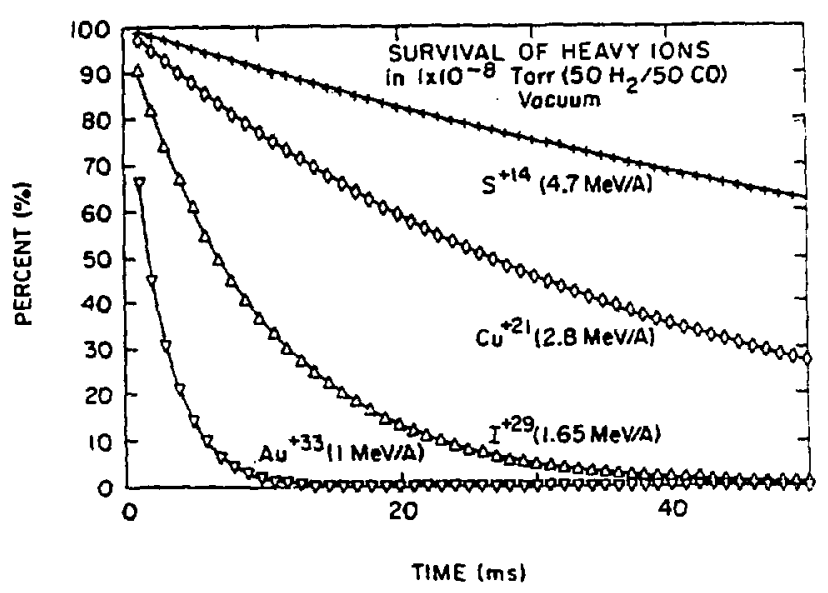

Figure 2 Heavy Ion Survival Rate

so that all ion species can be accelerated to high enough energy to be fully stripped before entering the AGS. Such a vacuum fulls into the ultra-high vecuum domin. The componeat processing and system design has been reviewed in Ref. [3] So far two-thirds of the ring has been baked out and pumped down to $3 \times 10^{11}$ Torr pressure.

\section{B. Wide Momentum Range}

The rescanant frequency of the Booster RF system, to properly accelerate all the intended ion species and protons, falls between $178 \mathrm{KHz}$ to $4.2 \mathrm{MHz}$. Such a wide range of frequency variation, about a factor of 22 , is impossible to achieve with the traditional tuning method of controlling the permeability of the ferrite inside the cavity. For reliable operation, three separate RF acceleration systems will be required if same harmonic number 3 is adopted for all three systems. The other possibility is to operate Band I and Band II at the sume frequency, but using hurmonic number 12 for low momentum acceleration and switch to harmonic number 3 for medium momentum acceleration. These two scenarios can be summarized in Table 1.

Table 1 RF Froquency (in MFiz) of Two Designs

\begin{tabular}{|c|c|c|c|}
\hline & $3+a d$ & 2004 & Buind II \\
\hline Desiga I & $0.18-0.68$ & $0.6-2.5$ & $2.4-4.2$ \\
\hline Design 2 & $0.72-2.50$ & $0.72-2.50$ & $2.4-4.2$ \\
\hline
\end{tabular}

Work performed under the auspice of the U. S. Dept. of Energy 


\section{DISCLAIMER}

This report was prepared as an account of work sponsored by an agency of the United States Government. Neither the United States Government nor any agency thereof, nor any of their employees, makes any warranty, express or implied, or assumes any legal liability or responsibility for the accuracy, completeness, or usefulness of any information, apparatus, product, or process disclosed, or represents that its use would not infringe privately owned rights. Reference herein to any specific commercial product. process, or service by trade name, trademark, manufacturer, or otherwise does not necessarily constitute or imply its endorsement, recommendation, or favoring by the United States Government or any agency thereof. The views and opinions of authors expressed herein do not necessarily state or reflect those of the United States Government or any agency thereof. 


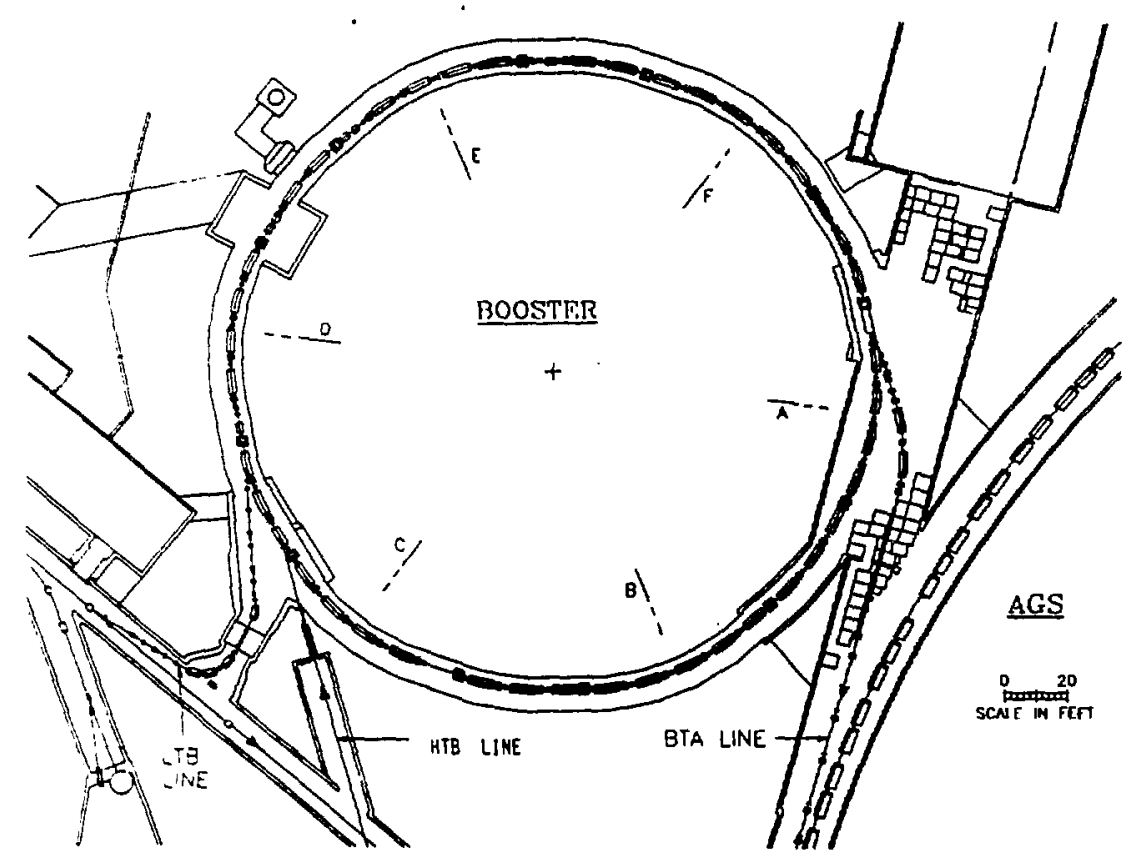

Figure 1 The Booster Location and Component Layout

There are advantages of operating two RF systems in an identical way. For example, it will result in more sccelerating volteges, a built-in a pair in case of emergency, running the Band I system at higher frequency belps to stay awny from the intrinsic ferrite instability at low frequency.

For proton acceleration, only the Band III system is roquired. The design voltuge of the cavity is $22.5 \mathrm{KV}$ per gap resulting in $90 \mathrm{~V}$ for two stations. Shown in Figure 3 is the output voltage of one gap providing $22.5 \mathrm{KV}$ in the upper trace and the cathode curreat varying from 5 to 8 amperes in the lower trace [4].

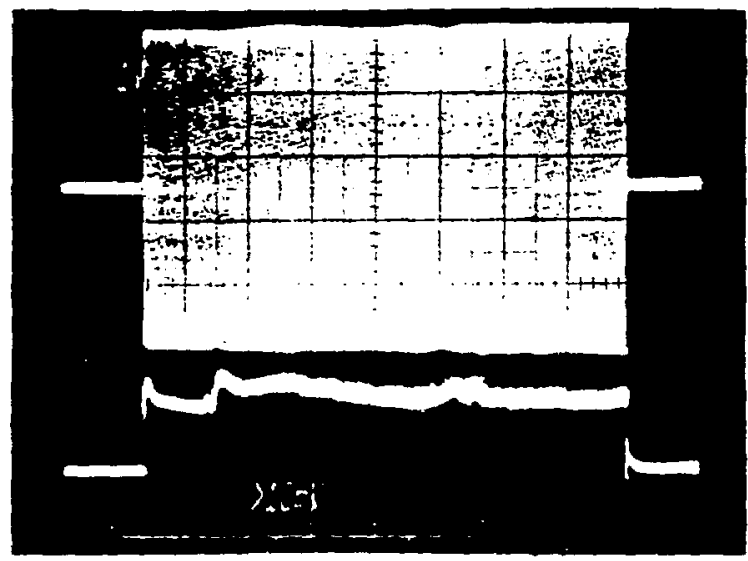

Figure 3 RF Voltage

The requirement to operate for wide momentum range is not unique for the RF system, it also applies to the beam position monitor (BPM) system. To design \& BPM system linear and stable for such a wide frequency is harder than that of a narrow frequeacy system. Stripline type electrodes were not chosen because of their narrow bandwidth and low signal level for heavy ion low inteasity application. The chosen design is the split cylinder capacitive pick-up electrode which can be made to provide sufficient response over a wide frequeacy range.[6] The offset of the electrical center line of the BPM system as a function of operating frequency can be made to be a linear function for high frequency application, but it will deviate more from this linear curve in the low frequency region. This effect introduces about $0.2 \mathrm{~mm}$ degradation in the accuracy of the position information for heavy ions.

For proton acceleration, the desired repetition rate is 7.5 $\mathrm{Hz}$, but that of heavy ion is about $1 \mathrm{~Hz}$. This adjustable rep rate requirement limits the design choice of the main magnet power supply system. Among the three possibilities considered, the resonence type is rulod out for its single frequency limitation, the motor-generator set appronch is too expensive, while the programmable multi-phase DC power supply controlled by SCRs has been chosen for its moderate cost and adjustable rep rate. A price to pay is the perturbation to the power distribution system of the utility company. Necessary protection measures has been discussod in reference [2].

To achieve fast cycling at $7.5 \mathrm{~Hz}, 12$ rectifier modules are connected in series [5]. Exch module is capable of delivering $433 \mathrm{~V}$ and $3000 \mathrm{~A}$. During heavy ion acceleration, 4 modules are used in series, each capable of supplying 6000 amperes. All 36 dipoles and 48 quadrupoles are connected in a series with additional quadrupole trim supplies for adjusting the tunes of the wccelerator. Shown in Figure 4 is the output from 2 modules of the power supply. The lower trace indicates the 
current ramped up to 1500 amps in 110 msec and the top trace shows the voltage steps.

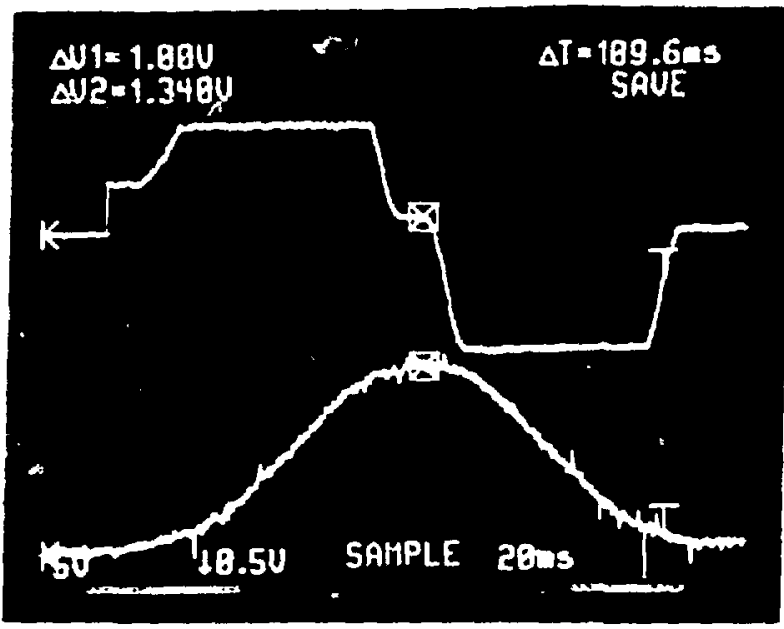

Figure 4 Power Supply Current Output

\section{Pulse-to-Pulse Modulation}

The requirements to run the Booster for different heavy ion species on a pulse-to-pulse basis is driven by the need to utilize the Booster for machine study during the long idle time between AGS pulses and the capability to collide different species in the RHIC. Two major problems could arise for such application. The first is the requirement to reset all the ring and transfer line components in one second. The second is the hysteresis of the magnetic component involved. So far, the most difficult situation is for alternate proton and heavy ion pulses. This is becsuse the required vacuum pressure for proton is the $10^{3}$ Torr range and that of the heavy ions is in the $10^{10}$ Torr range. High intensity, proton acceleration tends to heat up the vacuum chamber and cause excessive outgassing. Therefore, for the alternate proton and heavy ion application, the intensity of the proton has to be limited to allow for ultra-high vacuum condition.

Another special design consideration for accelerating different species in a pulse-to-pulse basis is the requirement on the control system. The Booster control system is Apollo based, hierarchical, distributed control system. Most of the operation is data base driven. To accommodate pulse-to-pulse acceleration, a super cycle generator structure has to be introduced such that a different set of "timing and data base instruction is selected for different applications (mini cycles) encompassed within the super-cycle. The pulse-to-pulse modulation design and examples of Linac-Booster-AGS super cycles has been presented by D. Barton [7].

\section{RESULTS of COMPONENT TESTS and BEAM COMMISSIONING}

The Booster ring employs 36 dipoles, 48 quadrupoles and 48 sextupoles. The design parameters of all the magnets are summarized in Table 2 . Very stringent magnet to magnet random errors are required for polarized proton acceleration. Higher order multipoles, both normel and skew components, up to order six of both dipoles and quadrupoles are all within the acceptable tolerances.

Table 2 Parameters of Booster Magnets

\begin{tabular}{|l|c|c|c|}
\hline & Dipole & Quedrupole & Sexpipole \\
\hline Number & 36 & 48 & 48 \\
\hline Length (m) & 2.34 & 0.47 & 0.10 \\
\hline Aperture (cm) & $8.25(\mathrm{v})$ & 8.25 & 8.25 \\
\hline Field & $1.27 \mathrm{~T}$ & $10 \mathrm{~T} / \mathrm{m}$ & $50 \mathrm{~T} / \mathrm{m}^{2}$ \\
\hline $\begin{array}{l}\text { Random Error } \\
\text { (Tolerance) }\end{array}$ & $1.5 \times 10^{-4}$ & $1 \times 10^{-3}$ & $2 \times 10^{-2}$ \\
\hline $\begin{array}{l}\text { Random Error } \\
\text { (Meanured) }\end{array}$ & $1.7 \times 10^{-4}$ & $0.4 \times 10^{-3}$ & $3.5 \times 10^{-3}$ \\
\hline
\end{tabular}

For the proton acceleration, the Booster has to run at $7.5 \mathrm{~Hz}$ rep rate. This will induce strong oddy current effects in the dipole vacuum chamber which is made of $2 \mathrm{~mm}$ thick inconel steel with an elliptical shape. The eddy current generates both dipole and sextupole fields. The dipole component can be corrected by adjusting the power supply. To compensate the sextupole field, a set of correction coils have been wound on a vacuum chamber giving linear current distribution in the radial direction [8]. A series resistor is chosen to cancel the sextupole field induced in the chamber. Shown in Figure 5 is the results of the testing. The lower trace of Figure 5 shows the sextupole field at several constant excitation current displaying the expected ion saturation effect at high field. The upper trace is the induced sextupole field at a ramp rate of $32.6 \mathrm{KA} / \mathrm{s}$ without the chamber correction coil connected. Figure 5B shows the same test with the chamber correction coil connected indicating that the eddy current induced sextupole field has been successfully canceled. Since this is a passive correction scheme independent of the ramp rate, the induced sextupole field is zero throughout the acceleration cycle. A detailed report on the magnetic measurement is given in Refereace [9].

Another important device employed in large quantities is the beam position monitor system. The mechanical structure of the pick-up-electrode is made of copper split cylinder $20 \mathrm{~cm}$ long and $7.5 \mathrm{~cm}$ in diameter. The design goal is to give \pm $0.1 \mathrm{~min}$ procision within $\pm 30 \mathrm{~mm}$ range. One design challenge is the reproducibility of the performance

before and after $900^{\circ}$ va uum firing and $200^{\circ}$ in-situ bakeout. Repetitive tests shows that the repeatability has been achieved. Each electrode has been calibrated for its electrical center line and linearity range by fitting the expression:

$$
\text { Position }=K \times \Delta / \Sigma+\text { offset }
$$


The parameters "offset" and the gain coefficients " $K$ " can be recorded in the database of the particular PUE for operation. On the other hand, the spread of those constant indicates the quality of the design and workmanship, and a total of 60 PUE measurements shows that the standard deviation of "offset" is $0.2 \mathrm{~mm}$ and that of " $\mathrm{K}$ " is 0.19 which gives an error of 0.07 $\mathrm{mm}$ without correction [10].
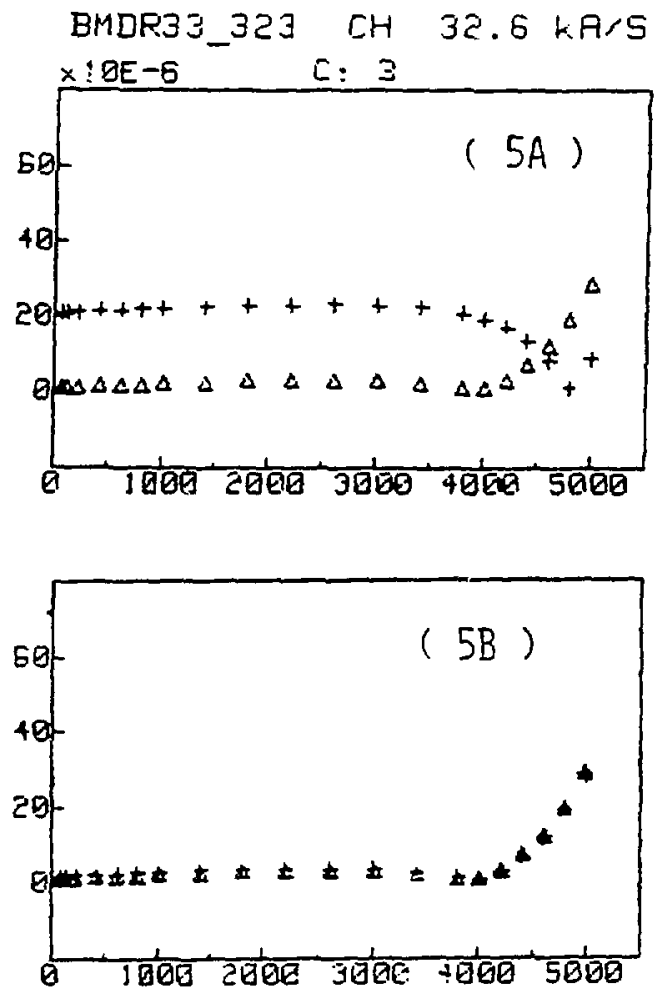

Figure 5 Eddy Current Induced Sextupole Field With Correction Coil Off (5A) and On (5B)

The Booster ring construction was completed by the end of April. All the magnetic components hes been tested and installed. The main magnet power supply system is in place and each module has been tested d.c. to 3000 amps and ramped at $5 \mathrm{~Hz}$ to 1500 amps. Shown in Figure 6 is the Booster ring at the proton injection area. Figure 7 shows part of the main magnet power supply gallery. In the left side is the twelve rectifier modules and in the right is the reference dipole magnet in series with the ring magnet. The precision field measurement device, the gauss clock, is installed for field detection providing timing triggers at injection, flattop and extraction.

So far, four sessions of beam commissioning have been performed [11]. The $200 \mathrm{MeV} \mathrm{H}$ beam has been successfully diverted from the end of the Linac into the LTB line, passed through the bored yoke of $\mathrm{CS}$ dipole, stripped into $\mathrm{H}^{+}$and propagated over one-sixth of the ring to a beam stop at D6.
As shown in Figure 1, the LTB line is 107 foet long and consists of 5 dipoles, 9 quadruples, 6 steering dipoles, 9 radiation loss monitors, 6 stripline type BPMS, 2 multiwire profile monitors, and 2 current transformers. The total angle of bend is $126^{\circ}$ with the dipole field limited to below $9 \mathrm{KG}$ to avoid $\mathrm{H}$ stripping by the field.

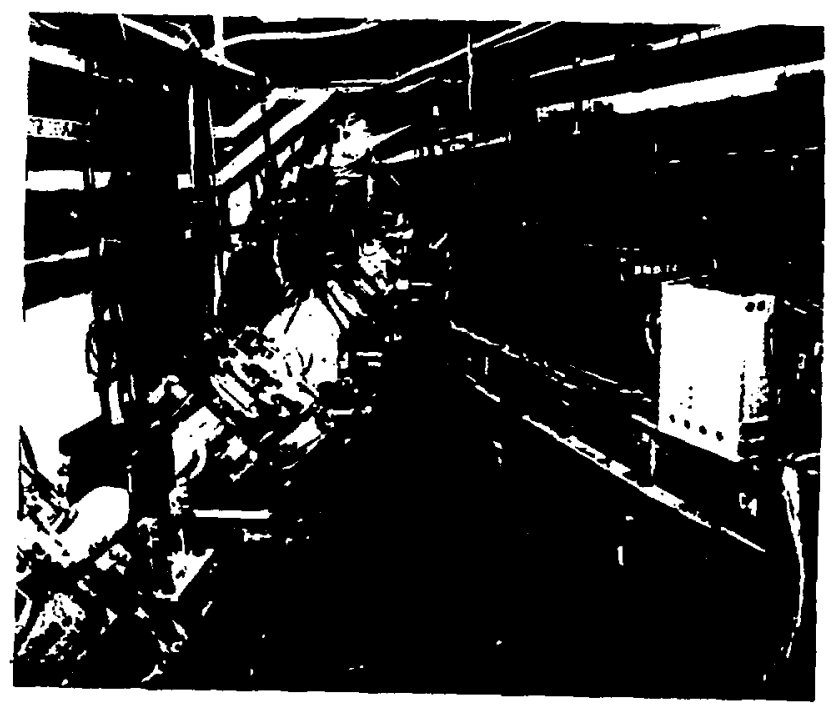

Figure 6 Booster Tunnel

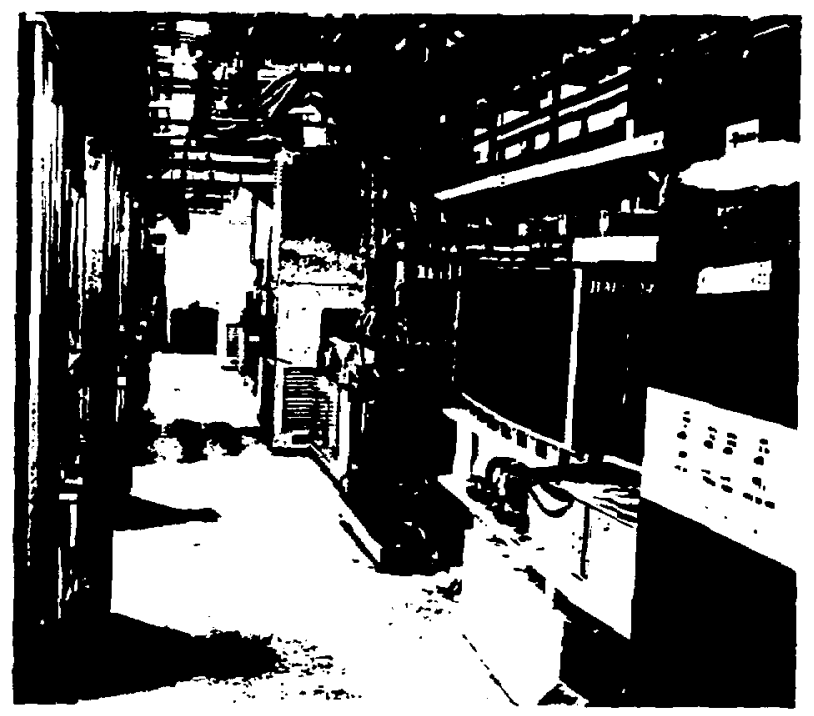

Figure 7 Power Supply Gallery

The display of the BPMS in the LTB line is given in Figure 8. It shows both horizontal and vertical trajectories have been corrected to better than $2 \mathrm{~mm}$ except at the end for injection. In fact, the final steering was accomplished by an AUTO-STEER program which made the orbit observation, calculating the required correction and made the correction automatically. 
An AUTO-EMIT program has also been implemented to vary the Q1-Q2-Q3 quadrupole as a triplet to sweep through the wist of the beam profile at the profile monitor downstream and perform a least square fit to obtain the beam emmitance at the entrance of the first switching magnet. Shown in Figure 8 is the display of 15 profiles as function of the strength of the triplet quadrupole Q1-Q2-Q3. A waist is visible in the middle of the ramp [12]. The fitted emittence of this preliminary nun is about $5 \mathrm{~mm}$-mrad, smaller than past measurements in the HEBT line. More measurement will be attempted when the commissioning resumes in May.
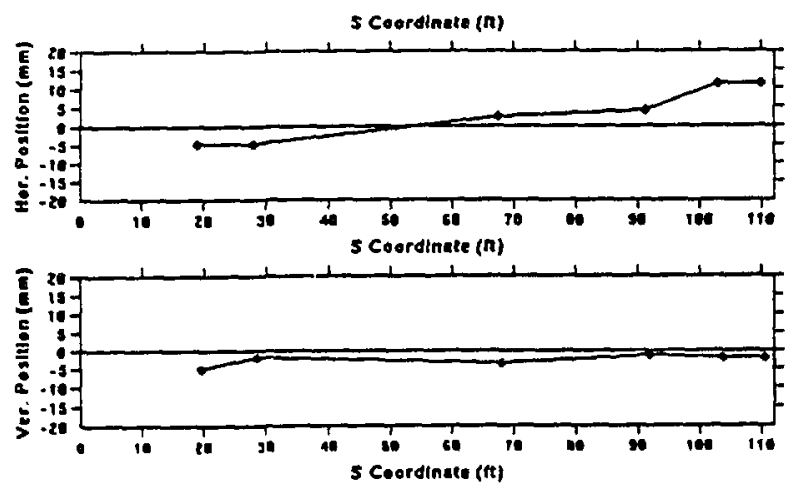

Figure 8 LTB Line BPM Display

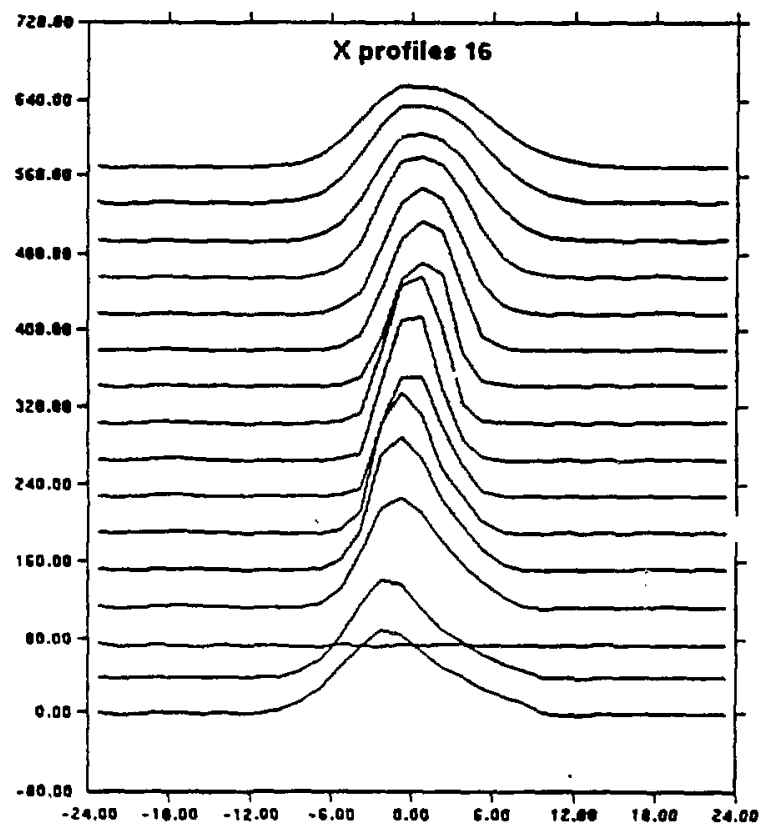

Figure 9 Profile Display from AUTO-EMIT
We plan to commission the Booster ring again in the third week of May. Orbit, tune, chromaticity and beam profiles in the ring will be measured. Acceleration and extraction will take place in June. Injection into the AGS and tuning for high intensity will be started after the summer shutdown. Heavy ion commissioning will be started in the spring of 1992.

To accelerate more then $2 \times 10^{13} \mathrm{p}$ per pulse in the AGS, the existing RF system and trunsverse demping system have to be upgraded. The new RF system will bave power amplifier pleced next to the cavity and a fast feedback correction scheme will be implemented to reduce beam loading and coupling impedance. A new and more powerful, bunch-to-bunch demper system will be implemented to suppress both the coupled bunch instability and injection errors from the Booster.

\section{ACKNOWLEDGEMENT}

The Booster construction and its commissioning were made possible by the staff of the Booster Project, AGS Department and ADD Department. Assistance from the Plent Engineering Div., Central Shops Div., Contract and Procurement Div. and Safety and Environmental Protection Div. are also essential for the Project.

\section{REFERENCES}

1. Booster Design Manual, BNL, October, 1988.

2. W.T. Weng, "Progress and Status of the AGS Booster Projoct", Particle Accelerators, Vol. 27, pp.13-20, 1990.

3. H.C. Hseuh, et al., "Processing and Evaluation of the AGS Booster UHV System", these proceedings, and H.C. Hseuh, "The AGS Booster Vacuum System", XI Intl. Vac. Cong., Vacuum, Vol. 41,pp.1903-1906 (1990).

4. R. Sanders, et al., "The AGS High Frequency RF System", these proceedings.

5. A. Soukas, et al., "The AGS Booster Main Ring Power Supply System", Particle Accelerators, Vol. 29, pp.121126, 1990.

6. R. Witkover, "New Beam Instrumentation in the AGS Booster", Adv. Beam Inst. Workshop, KEK, Japan, April, 1991.

7. D. Barton," The Development of Controls for Pulse-toPulse Modulation at the BNL AGS Complex", Inter. Conf. on Accel. and Large Expt. Phys. Control Systems, Vancouver, November, 1989.

8. G. Danby and J. Jackson, "Vacuum Chamber Eddy Current Self-Correction for the AGS Booster", Particle Accel., Vol. 27, pp. 33-38, 1990.

9. E. Bleser, "Analysis of Magnetic Field Measurement Results for the AGS Booster Magnets", these proceedings.

10. R. Thomas, D. Ciardullo, W. VanZwienen, 'Design and Testing of the AGS Booster BPM Detector", hese proceedings.

11. K. Reece, L. Ahrens, et al., "First Results of Proton Injection Commissioning of the AGS Booster", these proceedings.

12. J. Skelly, "Generalized Emittance Measurements in a Beam Transport Line", these proceedings. 